\title{
Management of Breast Cancer Patients with Chemotherapy-Induced Neutropenia or Febrile Neutropenia
}

\author{
Caterina Fontanella $a^{a, b}$ Silvia Bolzonello ${ }^{a}$ Bianca Lederer ${ }^{b} \quad$ Giuseppe Aprile $^{a}$ \\ a Department of Oncology, University Hospital of Udine, Italy \\ ${ }^{\mathrm{b}}$ German Breast Group, Neu-Isenburg, Germany
}

\section{Keywords}

Neutropenia - Febrile neutropenia - Prognostic score . Outpatients · Inpatients

\section{Summary}

Chemotherapy-induced neutropenia (CIN) is a common toxicity caused by the administration of anticancer drugs. This side effect is associated with life-threatening infections and may alter the chemotherapy schedule, thus impacting on early and long-term outcomes. Elderly breast cancer patients with impaired health status or advanced disease as well as patients undergoing dosedense anthracycline/taxane- or docetaxel-based regimens have the highest risk of CIN. A careful assessment of the baseline risk for CIN allows the selection of patients who need primary prophylaxis with granulocyte colony-stimulating factor (G-CSF) and/or antimicrobial agents. Neutropenic cancer patients may develop febrile neutropenia and CIN-related severe medical complications. Specific risk assessment scores, along with comprehensive clinical evaluation, are able to define a group of febrile patients with low risk for complications who can be safely treated as outpatients. Conversely, patients with higher risk of severe complications should be hospitalized and should receive intravenous antibiotic therapy with or without G-CSF.

\section{Introduction}

The worldwide incidence of breast cancer (BC) is increasing, accounting for $29 \%$ of all new cancer diagnoses in North American women and ranking second as the leading cause of death for malignancy $[1,2]$. However, over the last 6 decades, the mortality rate of $\mathrm{BC}$ patients has progressively decreased [3]. Among a number of different reasons, the improvement of chemotherapy strategies and the discovery of new anticancer drugs played a crucial role in prolonging the overall survival of BC patients.

The dose intensity is the total amount of drug delivered over the time course of the treatment. The relative dose intensity is the ratio of the delivered dose intensity to the reference dose intensity for a chemotherapy regimen [4]. A strong relationship exists between the relative dose intensity and the long-term outcome of BC patients diagnosed with chemosensitive tumors (such as cancer with a high proliferative index) [4-6]. It is important to maintain the optimal dose intensity in the adjuvant setting since the survival curves of patients treated with a relative dose intensity lower than $85 \%$ resemble those of untreated patients [7].

Chemotherapy-induced neutropenia (CIN) is the most common toxicity caused by the administration of anticancer drugs. In a large prospective registry, $37 \%$ of the $\mathrm{BC}$ patients experienced an absolute neutrophil count (ANC) lower than 500 cells $/ \mathrm{mm}^{3}$ over the first 4 cycles of treatment, and approximately $70 \%$ of the initial episodes occurred in cycle $1[8,9]$. CIN is associated with the risk of both life-threatening infections and chemotherapy dose reductions or delays that may reduce the relative dose intensity [10]. An analysis of over 1,100 BC patients treated with adjuvant cyclophosphamide, methotrexate, and fluorouracil (CMF), or doxorubicin and cyclophosphamide (AC), or other regimens showed that CIN was the most frequent cause of dose reductions and delays [11].

According to the latest version of the Common Terminology Criteria for Adverse Events (CTCAE) [12], neutropenia is defined as 'a finding based on laboratory test results that indicate a decrease in number of neutrophils in a blood specimen'. Since circulating neutrophils have a half-life of only 6-8 $\mathrm{h}$ after entering the peripheral blood, a rapid and efficient

\section{KARGER}

Fax +497614520714

Information@Karger.com

www.karger.com (c) 2014 S. Karger GmbH, Freiburg

$1661-3791 / 14 / 0094-0239 \$ 39.50 / 0$

Accessible online at:

www.karger.com/brc
Caterina Fontanella

University Hospital of Udine

Department of Medical Oncology

P.le Santa Maria della Misericordia, 15, 33100 Udine, Italy

fontanella.caterina@spes.uniud.it 
Fig. 1. Management of $B C$ patients with $C I N$ or patients who are expected to develop CIN, and FN, in the outpatient and inpatient setting. $\mathrm{ANC}=$ absolute neutrophil count, $\mathrm{G}-\mathrm{CSF}$ $=$ granulocyte colony-stimulating factor, $\mathrm{FN}$ = febrile neutropenia, $\mathrm{HBV}=$ hepatitis $\mathrm{B}$ virus, $\mathrm{BT}=$ body temperature, TMP-SMZ $=$ trimethoprim/sulfamethoxazole, MASCC $=$ Multinational Association for Supportive Care in Cancer risk index, $\mathrm{PCP}=$ primary care physician, IV = intravenous.

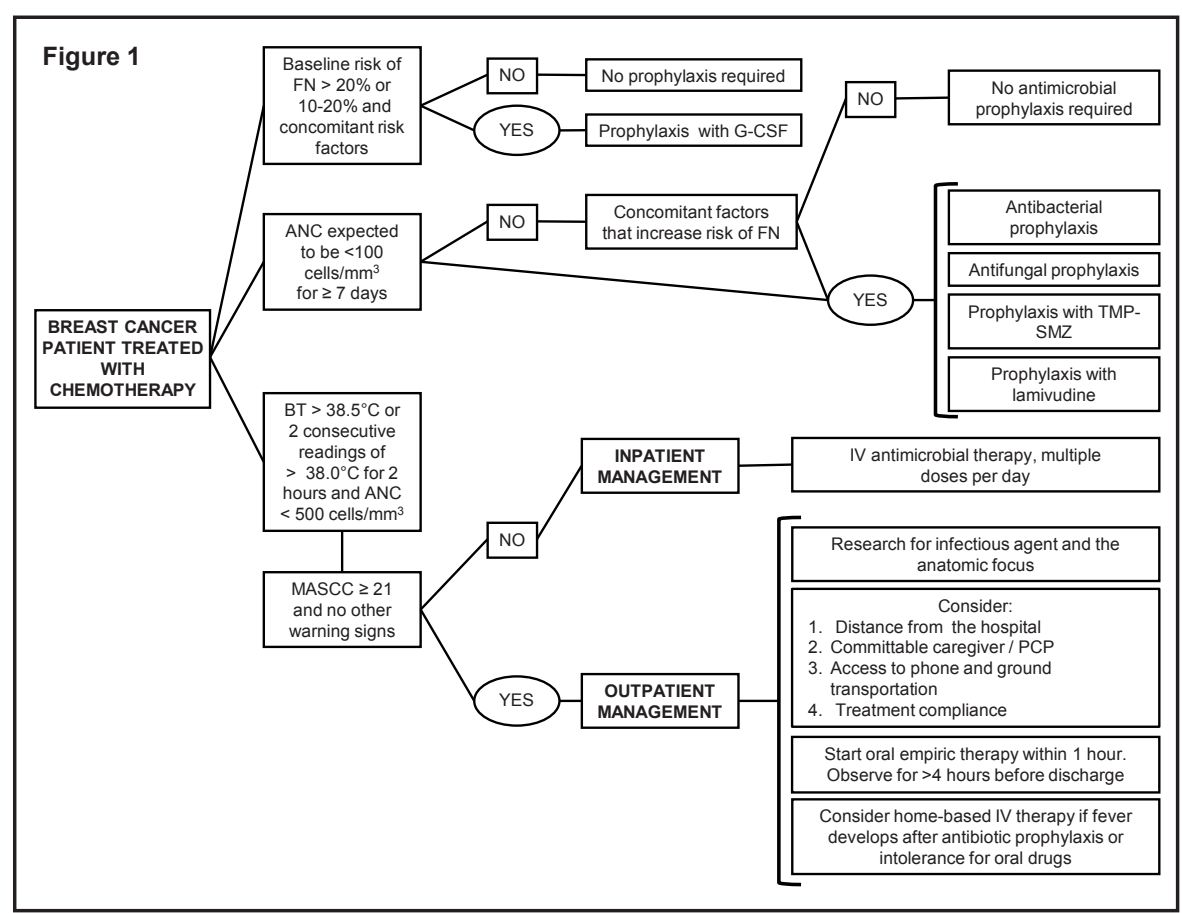

guidelines, $\mathrm{FN}$ is defined as an oral temperature $>38.5^{\circ} \mathrm{C}$ or two consecutive readings of $>38.0^{\circ} \mathrm{C}$ for $2 \mathrm{~h}$ and an $\mathrm{ANC}<$ 500 cells $/ \mathrm{mm}^{3}$ or expected to fall below this threshold.

\section{Risk of Developing Neutropenia}

Factors impacting on the risk of CIN can be grouped into patient-, disease-, and treatment-related factors.

Age is the most important patient-related risk factor; increasing age is associated with the greatest risk of CIN because of immunosenescence phenomena [19, 20]. Elderly patients may have reduced bone marrow reserves or declines in renal and hepatic function, and are more prone to treatment-related complications [21]. Similarly, patients with abnormal baseline laboratory values have a higher risk of CIN; in particular, aspartate aminotransferase $>35 \mu / 1$, alkaline phosphatase $>120$ $\mu / \mathrm{l}$, or total bilirubin $>1 \mathrm{mg} / \mathrm{dl}$ are associated with severe neutropenia or FN [21]. Moreover, patients with a poor performance status (PS) [21] or impaired nutritional status may have a compromised immune system due to deficiencies in proteins and micronutrients such as vitamins $\mathrm{C}$ and B6, zinc, iron, copper, and selenium [22]. Lastly, female patients have higher risks of CIN compared with male patients [21, 23, 24].

Disease-related factors include bone involvement, type of cancer, and previous history of myelotoxicity. Disease extension is a significant predictor for neutropenia, FN, septic shock, and death [24]. Overall, patients with hematologic cancers are at greater risk for myelosuppression than patients with solid tumors [24]. Moreover, a low baseline and first-cy- cle nadir white blood cell count and high chemotherapy dose intensity are significant predictors of neutropenic events [24].

Treatment-related risk factors for developing CIN include radiation therapy to the bone marrow, type of prior chemotherapy, and treatment regimen. BC patients exposed to dosedense anthracycline/taxane- and docetaxel-based regimens have a $>20 \%$ risk of developing neutropenia [25]. A recent Korean study showed that the incidence of FN in BC patients who received AC for 4 cycles followed by docetaxel (D) for 4 cycles or docetaxel, adriamycin, and cyclophosphamide (TAC) for 6 cycles without primary granulocyte colony-stimulating factor (G-CSF) prophylaxis was $29.7 \%$ and $63.4 \%$, respectively [26]. However, the overall taxane-induced toxicity reported in the literature is higher in Asian compared with Caucasian populations [27]. Furthermore, the vast majority of the standard regimens used in clinical practice are associated with an intermediate risk of neutropenia (10-20\%) [27].

\section{Management of Neutropenia}

\section{Baseline Risk Assessment}

$\mathrm{BC}$ patients have an average risk for $\mathrm{FN}$ of $4.4 \%$, but several different factors could affect this value [16]. Thus, in patients with CIN or in those expected to become neutropenic, a comprehensive systematic risk assessment for $\mathrm{FN}$ is mandatory.

Patients $\geq 65$ years, with advanced disease, an Eastern Cooperative Oncology Group (ECOG) PS $>1$, an albumin concentration $<35 \mathrm{~g} / \mathrm{l}$, or with significant comorbid conditions 
have an increased risk of developing FN. Moreover, patients whose disease is progressing despite the treatments given are more likely to experience complications compared to those who achieve a complete/partial response (table 1).

In the risk assessment of neutropenic patients, characteristics related to the treatment and the reported adverse events should also be taken into account. The risk of neutropenic complications is higher if an anthracycline/taxane- or an anthracycline/gemcitabine-based regimen is administered. Moreover, severe mucositis, severe neutropenia for at least 1 week, lymphopenia of $<700$ cells $/ \mathrm{mm}^{3}$, and monocytopenia of $<150$ cells $/ \mathrm{mm}^{3}$ are all associated with a higher risk of neutropenic complications (table 1).

\section{Prophylaxis in Non-Febrile Neutropenic Outpatients}

The international guidelines recommend primary prophylaxis with G-CSF whenever the risk of FN is $>20 \%[19,27$, 28]. Both the National Comprehensive Cancer Network (NCCN) [27] and the ASCO guidelines [29] recommend the use of G-CSF for chemotherapy administered every 3 weeks, but not for weekly chemotherapy regimens. Antibacterial, antiviral, and antifungal prophylaxis should be considered only for patients expected to experience profound neutropenia likely to last longer than 1 week or in very select cases (fig. 1) [16]. On the other hand, patients with severe neutropenia but with a good PS and without risk factors for the development of complications could be only closely monitored until ANC recovery (table 1). An antibacterial prophylaxis with oral fluoroquinolones is recommended to prevent invasive infection by Gram-negative bacilli in outpatients with profound neutropenia and mucositis expected to last for at least 7 days. The use of an orally administered triazole antifungal is recommended in the outpatient setting as prophylaxis in patients with $>10 \%$ risk of invasive Candida infection. Prophylaxis with trimethoprim/sulfamethoxazole should only be used if the risk of pneumonia from Pneumocystis jirovecii is $>3.5 \%$. Lamivudine is recommended as prophylaxis in patients at high risk for reactivation of hepatitis B virus (HBV) infection (fig. 1) [16].

The primary prophylaxis of seasonal influenza with a trivalent inactive vaccine is suggested in all patients receiving chemotherapy [30].

\section{Management of Febrile Neutropenia}

\section{Risk Assessment for the Development of Medical Complications}

All patients who experienced CIN have a risk of developing FN potentially followed by serious medical problems. However, the risk may depend on previous neutropenic complications. Based on a review of chemotherapy-based regimens in the Breast Cancer Canadian Database Initiative, 72\% of the patients reporting a first episode of neutropenic complication experienced further medical problems during following treatment cycles [29].

FN represents a heterogeneous condition with different patient outcomes. As a result, a number of decision-making models and scoring systems have been validated as guidelines for its upfront management.

The Multinational Association for Supportive Care in Cancer (MASCC) risk index allows the prediction of complications taking into account the type and the burden of illness and related symptoms, the presence of hypotension, chronic obstructive pulmonary disease, previous fungal infection, and dehydration, the age of the patient, and the outpatient status (table 2) [31]. In solid malignancies, a MASCC score $\geq 21$ identifies a subgroup of patients at low risk for complications.

Although the MASCC risk index has been validated in several publications over the last decade [32,33], additional clinical criteria should be considered during a patient's baseline risk assessment. Patients with significant cardiovascular disease, and patients with impaired liver or renal function, should be considered at increased risk even if they have a MASCC score $\geq 21$. Accordingly, patients with active/possible sites of infection, altered mental status or any other sign or symptom of central nervous system involvement, or with gastrointestinal disturbance should be considered at higher risk and managed carefully. Finally, ascites, pleural or pericardial effusion, pancytopenia, electrolyte abnormalities or renal impairments also need to be considered.

\section{Treatment of FN in the Out- and Inpatient Setting}

Bacterial infection is the most frequent cause of fever in cancer patients [34]. For this reason, BC patients with an oral body temperature $>38.5^{\circ} \mathrm{C}$ should undergo a clinical interview, an accurate physical examination, laboratory tests including complete blood count, electrolytes and creatinine, and a radiological assessment according to clinical suspicions, in order to maximize the possibility of a microbiologic diagnosis that may require specific antibacterial treatment [35].

As mentioned previously, once febrile patients have been carefully examined for infections and FN has been diagnosed, a risk assessment for complications is mandatory. Identification of patients suitable for outpatient management is crucial since this cost-effective strategy allows savings, limits the risk of hospital-acquired infections and improves the patients' quality of life [36, 37]. FN patients with a MASCC score $\geq 21$ and without other clinical warning signs can be safely managed in the outpatient setting if they are able to take oral medication and have a committed caregiver [38, 39]. Successful management of CIN in $\mathrm{BC}$ outpatients requires the patients and their caregivers to be educated to rapidly recognize signs and symptoms of possible infection. Furthermore, it is essential to provide them with written instructions on when and how to contact health care practitioners. Ideally, FN candidates eligible for outpatient management require: (1) resi- 


\begin{tabular}{|c|c|c|}
\hline \multicolumn{2}{|l|}{ Factors } & \multirow{2}{*}{$\begin{array}{l}\text { Score } \\
5\end{array}$} \\
\hline Burden of symptoms & no or mild symptoms & \\
\hline & moderate symptoms & 3 \\
\hline & severe symptoms & 0 \\
\hline \multirow[t]{2}{*}{ Blood pressure } & systolic blood pressure $>90 \mathrm{mmHg}$ & 5 \\
\hline & systolic blood pressure $\leq 90 \mathrm{mmHg}$ & 0 \\
\hline \multirow[t]{2}{*}{ Chronic obstructive pulmonary disease } & no & 4 \\
\hline & yes & 0 \\
\hline \multirow[t]{2}{*}{ Previous fungal infection } & no & 4 \\
\hline & yes & 0 \\
\hline \multirow[t]{2}{*}{ Dehydration requiring parenteral fluids } & no & 3 \\
\hline & yes & 0 \\
\hline \multirow[t]{2}{*}{ Onset of fever } & in outpatient status & 3 \\
\hline & in inpatient status & 0 \\
\hline \multirow[t]{2}{*}{ Age } & $<60$ years & 2 \\
\hline & $\geq 60$ years & 0 \\
\hline \multicolumn{3}{|l|}{ Total score } \\
\hline \multicolumn{3}{|c|}{$\begin{array}{l}\text { Total score } \geq 21 \text { points: patients with a low risk for serious complications of FN (including de } \\
\text { mission, confusion, cardiac complications, respiratory failure, renal failure, hypotension, blee } \\
\text { cal complications). } \\
\text { Total score }<21 \text { points: patients with a high risk for serious complications of FN. }\end{array}$} \\
\hline
\end{tabular}

dence at $<1 \mathrm{~h}$ from the hospital, (2) agreement of the primary care physician to outpatient management, (3) the ability to observe logistic requirements, (4) the presence of a caregiver $24 \mathrm{~h}$ a day, (5) access to a telephone and transportation $24 \mathrm{~h} \mathrm{a}$ day, (6) the absence of a history of non-compliance with treatment protocols (fig. 1) [16].

A meta-analysis of 22 trials showed similar mortality and treatment failure rates between oral and intravenous antibiotic treatment [38]. The analysis confirmed that oral treatment is a reasonable option in FN patients who are hemodynamically stable and have no organ failure, pneumonia, or a central line or severe soft-tissue infection. Similar safety and efficacy of oral versus intravenous therapy as initial empiric therapy have also been demonstrated in a Cochrane review [39]. According to the ASCO guidelines [16], cancer patients with FN at low risk of complications should be treated as outpatients and should receive a combination of oral fluoroquinolones (ciprofloxacin or levofloxacin) and amoxicillin/clavulanate (or clindamycin in patients allergic to penicillin) (fig. 1). According to a recent study, oral moxifloxacin administered once daily could be considered as efficacious and safe as amoxicillin/clavulanate in low-risk FN outpatients [40]. Oral medication intolerance may be circumvented in exceptional cases with home-based intravenous administrations. Notably, the first administration of therapy should be given in the hospital within $1 \mathrm{~h}$ from the diagnosis of $\mathrm{FN}$, and patients selected for outpatient management should be monitored for at least $4 \mathrm{~h}$ before discharge, to verify clinical stability [16, 41].

A recent study reported that almost $40 \%$ of patients with a respiratory tract infection due to Staphylococcus aureus were resistant to ciprofloxacin, and similar results were observed in patients with urinary tract infections due to Escherichia coli
[42]. In patients who developed fever after a fluoroquinolonebased primary prophylaxis, or if a prevalence of fluoroquinolone resistance $>20 \%$ has been documented, intravenous therapy is still suitable for outpatient administration (fig. 1). However, if patients are infected by fluoroquinolone-resistant Gram-negative pathogens that are co-resistant to $\beta$-lactams, inpatient management and administration of meropenem every $8 \mathrm{~h}$ or piperacillin/tazobactam every $6 \mathrm{~h}$ are required. Similarly, patients with FN at high or intermediate risk need to be hospitalized for intravenous antimicrobial therapy (fig. 1). In these patients, local epidemiological bacterial isolate and resistance patterns are crucial in determining the firstchoice empirical therapy.

G-CSF should not be routinely used in patients with FN. However, in high-risk patients, the use of G-CSF could be considered as adjunctive treatment with antibiotic therapy [29].

\section{Conclusions}

In $\mathrm{BC}$ patients, $\mathrm{FN}$ is relatively common. Up to $23 \%$ of them experience at least 1 episode of FN secondary to standard chemotherapy, and this figure skyrockets to $98 \%$ in patients exposed to high-dose chemotherapy regimens [43, 44].

A recent case-control study showed that $\mathrm{FN}$ is associated with higher health care resource use in $\mathrm{BC}$ patients compared to non-FN patients [45]. BC patients with a history of FN had an increased risk of all-cause hospitalization in the first month after the febrile event compared with patients who never experienced $\mathrm{FN}$ (odds ratio $(\mathrm{OR})=23.0,95 \%$ confidence interval (CI) 8.3-63.7) and they also had a longer median length of 
stay of all-cause hospitalizations (4 days vs. 1 day). Moreover, regardless of the type of cancer diagnosed, the length of hospital stay for FN patients is 6.5-8.8 days [46, 47], with an overall cost of USD 15,231 per FN episode or USD 1,455 per day of hospitalization [48].

An Australian cost analysis showed a 30\% saving for ambulatory care strategies when compared with standard hospital care [49]. Considering the high economic cost for the health care system of hospitalized BC patients with FN, managing as many patients as possible in an outpatient setting should be a key task in modern medical oncology.

Moreover, outpatient management of low-risk FN patients is safe and cost-effective. In a sample of more than 700 patients with low-risk FN, the response rate to the empirical antibiotic regimen was $81 \%$ in outpatients and $80 \%$ in inpatients $(\mathrm{p}=0.94)$. Moreover, the mean durations of the fever (2.0 vs. 2.4 days; $p=0.04$ ) and the antibiotic therapy (8.5 vs. 9.2 days; $\mathrm{p}=0.08)$ were significantly shorter among outpatients compared with inpatients [38]. Accordingly, a Cochrane review demonstrated that oral antibiotic treatment is an acceptable alternative to intravenous treatment in selected FN cancer patients [38]. The mortality rate was 32 out of 1000 patients treated with an intravenous antibiotic regimen versus 30 out of 1000 patients treated with an oral regimen (risk ratio (RR) $=0.95,95 \%$ CI $0.54-1.68$ ).

As expected, a health-related quality-of-life study showed that $75 \%$ of patients preferred an outpatient strategy for FN. In particular, $36 \%$ preferred an outpatient management with oral antibiotics, $21 \%$ an outpatient management with intravenous antibiotics, and $18 \%$ an oral treatment at home after an initial observation in the hospital [37].

In conclusion, improving the outpatient management of low-risk FN patients will have a positive impact not only on cost saving but also on the patients' quality of life.

\section{Disclosure Statement}

The authors did not provide a disclosure statement.

\section{References}

-1 Siegel R, Ma J, Zou Z, Jemal A: Cancer statistics, 2014. CA Cancer J Clin 2014;64:9-29.

2 de Azambuja E, Ameye L, Paesmans M, Zielinski CC, Piccart-Gebhart M, Preusser M: The landscape of medical oncology in Europe by 2020. Ann Oncol 2014;25:525-528.

3 MD Anderson Cancer Center: MD Anderson study finds increases in five, 10-year survival at every stage of breast cancer over six decades. News Release 09/29/10,www.mdanderson.org/newsroom/ news-releases $/ 2010 / m d$-anderson-study-finds-increases-in-five-10-year-survival-at-every-stage-ofbreast-cancer-over-six-decades.html [accessed 28 April 2014]

4 Lyman GH, Dale DC, Crawford J: Incidence and predictors of low dose-intensity in adjuvant breast cancer chemotherapy: a nationwide study of community practices. J Clin Oncol 2003;21:4524-4531.

5 Loibl S, Skacel T, Nekljudova V, Lück HJ, Schwenkglenks M, Brodowicz T, Zielinski C, von Minckwitz G: Evaluating the impact of relative total dose intensity (RTDI) on patients' short and long-term outcome in taxane- and anthracyclinebased chemotherapy of metastatic breast cancer - a pooled analysis. BMC Cancer 2011;11:131.

6 Griffin DA, Penprase B, Klamerus JF: Relative dose intensity - improving treatment and outcomes in early-stage breast cancer: a retrospective study. Oncol Nurs Forum 2012;39:E459-E467.

7 Bonadonna G, Moliterni A, Zambetti M, Daidone MG, Pilotti S, Gianni L, Valagussa P: 30 years' follow up of randomised studies of adjuvant CMF in operable breast cancer: cohort study. BMJ 2005; 330:217.

8 Crawford J, Wolff DA, Culakova E, Poniewiersk MS, Selby C, Dale DC, Lyman GH: First cycle risk of severe and febrile neutropenia in cancer patients receiving systemic chemotherapy: results from a prospective nationwide study. Blood 2004;104: 607a-608a, abstr 2210.
9 Culakova E, Thota R, Poniewierski MS, Kuderer NM, Wogu AF, Dale DC, Crawford J, Lyman GH: Patterns of chemotherapy-associated toxicity and supportive care in US oncology practice: a nationwide prospective cohort study. Cancer Med 2014; 3:434-444.

10 Crawford J, Dale DC, Lyman GH: Chemotherapyinduced neutropenia: risks, consequences, and new directions for its management. Cancer 2004;100:228-237.

11 Link BK, Budd GT, Scott S, Dickman E, Paul D, Lawless G, Lee MW, Fridman M, Ford J, Carter WB: Delivering adjuvant chemotherapy to women with early-stage breast carcinoma: current patterns of care. Cancer 2001;92:1354-1367.

12 Common Terminology Criteria for Adverse Events (CTCAE), version 4.0. http://evs.nci.nih.gov/ftp1/ CTCAE/CTCAE_4.03_2010-06-14_ QuickReference_5x7.pdf [accessed 28 April 2014].

13 Bhatt V, Saleem A: Review: Drug-induced neutropenia - pathophysiology, clinical features, and management. Ann Clin Lab Sci 2004;34:131-137.

14 Friberg LE, Henningsson A, Maas H, Nguyen L, Karlsson MO: Model of chemotherapy-induced myelosuppression with parameter consistency across drugs. J Clin Oncol 2002;20:4713-4721.

15 Bodey GP, Buckley M, Sathe YS, Freireich EJ: Quantitative relationships between circulating leukocytes and infection in patients with acute leukemia. Ann Intern Med 1966;64:328-340.

16 Flowers CR, Seidenfeld J, Bow EJ, Karten C, Gleason C, Hawley DK, Kuderer NM, Langston AA, Marr KA, Rolston KV, Ramsey SD: Antimicrobial prophylaxis and outpatient management of fever and neutropenia in adults treated for malignancy: American Society of Clinical Oncology clinical practice guideline. J Clin Oncol 2013;31: 794-810.
17 de Naurois J, Novitzky-Basso I, Gill MJ, Marti FM, Cullen MH, Roila F; ESMO Guidelines Working Group: Management of febrile neutropenia: ESMO clinical practice guidelines. Ann Oncol 2010;21 (suppl 5):v252-v256.

18 Aapro MS, Bohlius J, Cameron DA, Dal Lago L, Donnelly JP, Kearney N, Lyman GH, Pettengell R, Tjan-Heijnen VC, Walewski J, Weber DC, Zielinski C; European Organisation for Research and Treatment of Cancer: 2010 update of EORTC guidelines for the use of granulocyte-colony stimulating factor to reduce the incidence of chemotherapy-induced febrile neutropenia in adult patients with lymphoproliferative disorders and solid tumours. Eur J Cancer 2011;47:8-32.

19 Crighton M, Puppione A: Geriatric neutrophils: implications for older adults. Semin Oncol Nurs 2006;22:3-9.

20 Lyman GH, Abella E, Pettengell R: Risk factors for febrile neutropenia among patients with cancer receiving chemotherapy: a systematic review. Crit Rev Oncol Hematol 2014;90:190-199.

21 Balducci L, Hardy CL, Lyman GH: Hemopoiesis and aging. Cancer Treat Res 2005;124:109-134.

22 Wardwell L, Chapman-Novakofski K, Herrel S, Woods J: Nutrient intake and immune function of elderly subjects. J Am Diet Assoc 2008;108:20052012.

23 Lyman GH, Lyman CH, Agboola O: Risk models for predicting chemotherapy-induced neutropenia. Oncologist 2005;10:427-437.

24 Weycker D, Li X, Edelsberg J, Barron R, Kartashov A, Xu H, Lyman GH: Risk of febrile neutropenia in patients receiving emerging chemotherapy regimens. Support Care Cancer 2014 [Epub ahead of print].

25 NCCN guidelines: Myeloid growth factors. $w w w$. nccn.org/professionals/physician_gls/pdf/myeloid_ growth.pdf [accessed28 April 2014]. 
26 Lee J, Ahn MH, Jang YH, Lee EJ, Park JH, Rho J, Kim Z, Kim HM, Han SW, Lim C, Lee MH, Kim SY: Toxicity and quality of life of Korean breast cancer patients treated with docetaxel-containing chemotherapy without primary G-CSF prophylaxis. Breast Cancer 2013 [Epub ahead of print].

27 Millward MJ, Boyer MJ, Lehnert M, Clarke S, Rischin D, Goh BC, Wong J, McNeil E, Bishop JF: Docetaxel and carboplatin is an active regimen in advanced non-small-cell lung cancer: a phase II study in Caucasian and Asian patients. Ann Oncol 2003;14:449-454.

28 Smith TJ, Khatcheressian J, Lyman GH, Ozer H, Armitage JO, Balducci L, Bennett CL, Cantor SB, Crawford J, Cross SJ, Demetri G, Desch CE, Pizzo PA, Schiffer CA, Schwartzberg L, Somerfield MR, Somlo G, Wade JC, Wade JL, Winn RJ, Wozniak AJ, Wolff AC: 2006 update of recommendations for the use of white blood cell growth factors: an evidence-based clinical practice guideline. J Clin Oncol 2006;24:3187-3205.

29 Chang J: Chemotherapy dose reduction and delay in clinical practice: evaluating the risk to patient outcome in adjuvant chemotherapy to breast cancer. Eur J Cancer 2000;36:S11-S14.

30 Pedrazzoli P, Baldanti F, Donatelli I, Castrucci MR, Puglisi F, Silvestris N, Cinieri S: Vaccination for seasonal influenza in patients with cancer: recommendations of the Italian Society of Medical Oncology (AIOM). Ann Oncol 2014;25:1243-1247.

31 Klastersky J, Paesmans M, Rubenstein EB, Boyer M, Elting L, Feld R, Gallagher J, Herrstedt J, Rapoport B, Rolston K, Talcott J: The Multinational Association for Supportive Care in Cancer risk index: a multinational scoring system for identifying low-risk febrile neutropenic cancer patients. J Clin Oncol 2000;18:3038-3051.

-32 Uys A, Rapoport BL, Anderson R: Febrile neutropenia: a prospective study to validate the Multinational Association of Supportive Care of Cancer (MASCC) risk-index score. Support Care Cancer 2004;12:555-560.

33 Klastersky J, Paesmans M: The Multinational Association for Supportive Care in Cancer (MASCC) risk index score: 10 years of use for identifying lowrisk febrile neutropenic cancer patients. Support Care Cancer 2013;21:1487-1495.
34 Toussaint E, Bahel-Ball E, Vekemans M, Georgala A, Al-Hakak L, Paesmans M, Aoun M: Causes of fever in cancer patients (prospective study over 477 episodes). Support Care Cancer 2006;14:763-769.

$35 \mathrm{NCCN}$ guidelines: Prevention and treatment of cancer-related infections. www.nccn.org/professionals/ physician_gls/pdf/infections.pdf [accessed28 April 2014]

36 Hendricks AM, Loggers ET, Talcott JA: Costs of home versus inpatient treatment for fever and neutropenia: analysis of a multicenter randomized trial. J Clin Oncol 2011;29:3984-3989.

37 Teuffel O, Cheng S, Ethier MC, Diorio C, Martino J, Mayo C, Wing R, Sung L, Alibhai SM: Healthrelated quality of life anticipated with different management strategies for febrile neutropenia in adult cancer patients. Support Care Cancer 2012;20:2755-2764.

38 Vidal L, Ben Dor I, Paul M, Eliakim-Raz N, Pokroy E, Soares-Weiser K, Leibovici L: Oral versus intravenous antibiotic treatment for febrile neutropenia in cancer patients. Cochrane Database Syst Rev 2013;(10):CD003992.

39 Vidal L, Paul M, Ben-Dor I, Pokroy E, SoaresWeiser K, Leibovici L: Oral versus intravenous antibiotic treatment for febrile neutropenia in cancer patients. Cochrane Database Syst Rev 2004;(4): CD003992.

40 Kern WV, Marchetti O, Drgona L, Akan H, Aoun M, Akova M, de Bock R, Paesmans M, Viscoli C, Calandra T: Oral antibiotics for fever in low-risk neutropenic patients with cancer: a double-blind, randomized, multicenter trial comparing single daily moxifloxacin with twice daily ciprofloxacin plus amoxicillin/clavulanic acid combination therapy - EORTC infectious diseases group trial XV. J Clin Oncol 2013;31:1149-1156.

41 Dellinger RP, Levy MM, Carlet JM, Bion J, Parker MM, Jaeschke R, Reinhart K, Angus DC, BrunBuisson C, Beale R, Calandra T, Dhainaut JF, Gerlach H, Harvey M, Marini JJ, Marshall J, Ranieri M, Ramsay G, Sevransky J, Thompson BT, Townsend S, Vender JS, Zimmerman JL, Vincent JL: Surviving Sepsis Campaign: international guidelines for management of severe sepsis and septic shock: 2008. Intensive Care Med 2008;34:17-60.

42 Anvari MS, Naderan M, Boroumand MA, Shoar S, Bakhshi R, Naderan M: Microbiologic spectrum and antibiotic susceptibility pattern among patients with urinary and respiratory tract infection. Int $\mathrm{J}$ Microbiol 2014;2014:682304.
3 Rahman Z, Esparza-Guerra L, Yap HY, Fraschini G, Bodey G, Hortobagyi G: Chemotherapy-induced neutropenia and fever in patients with metastatic breast carcinoma receiving salvage chemotherapy. Cancer 1997;79:1150-1157.

44 O'Shaughnessy JA, Denicoff AM, Venzon DJ, Danforth D, Pierce LJ, Frame JN, Bastian A, Ghosh B, Goldspiel B, Miller L: A dose intensity study of FLAC (5-fluorouracil, leucovorin, doxorubicin, cyclophosphamide) chemotherapy and Escherichia coli-derived granulocyte-macrophage colony-stimulating factor (GM-CSF) in advanced breast cancer patients. Ann Oncol 1994;5:709-716.

45 Issa DE, Gelderblom H, Lugtenburg PJ, van Herk-Sukel MP, Houweling LM, De La Orden M, van der Werf-Langenberg ME, Nortier JW, de Jong FA: Healthcare utilisation in patients with breast cancer or non-Hodgkin lymphoma who experienced febrile neutropenia in The Netherlands: a retrospective matched control study using the PHARMO database. Eur J Cancer Care (Engl) 2014 [Epub ahead of print].

46 Innes H, Lim SL, Hall A, Chan SY, Bhalla N, Marshall E: Management of febrile neutropenia in solid tumours and lymphomas using the Multinational Association for Supportive Care in Cancer (MASCC) risk index: feasibility and safety in routine clinical practice. Support Care Cancer 2008;16:485-491.

47 Courtney DM, Aldeen AZ, Gorman SM, Handler JA, Trifilio SM, Parada JP, Yarnold PR, Bennett CL: Cancer-associated neutropenic fever: clinical outcome and economic costs of emergency department care. Oncologist 2007;12:1019-1026.

48 Elting LS, Lu C, Escalante CP, Giordano SH, Trent JC, Cooksley C, Avritscher EB, Shih YC, Ensor J, Bekele BN, Gralla RJ, Talcott JA, Rolston K: Outcomes and cost of outpatient or inpatient management of 712 patients with febrile neutropenia. J Clin Oncol 2008;26:606-611.

49 Lingaratnam S, Worth LJ, Slavin MA, Bennett CA, Kirsa SW, Seymour JF, Dalton A, Koczwara B, Prince HM, O'Reilly M, Mileshkin L, Szer J, Thursky KA: A cost analysis of febrile neutropenia management in Australia: ambulatory v. inhospital treatment. Aust Health Rev 2011;35:491500 . 